\title{
Distilled Spirit Extraction of Phenolic Antioxidants from Fruit and Vegetable Residues
}

\author{
Cesar V. Ortinero ${ }^{1,2^{*}}$, Rosalie R. Rafael ${ }^{2}$, Charmaine Eljie R. Rayos ${ }^{2}$, \\ Katherine D.A. Bautista ${ }^{1}$, Mark Aldren M. Feliciano ${ }^{2}$, Lexter R. Natividad ${ }^{3}$, \\ Gaudencio M. Natividad 2,4
}

1 Department of Environmental Science, College of Science, Central Luzon State University, Science City of Muñoz 3120, Nueva Ecija, Philippines

2 Department of Chemistry, College of Science, Central Luzon State University, Science City of Muñoz 3120, Nueva Ecija, Philippines

${ }^{3}$ University Science High School, College of Education, Central Luzon State University, Science City of Muñoz 3120, Nueva Ecija, Philippines

${ }^{4}$ (Present Address) Philippine Science High School - Cagayan Valley Campus, Bayombong 3700, Nueva Vizcaya, Philippines

*Corresponding author: cvortinero@clsu.edu.ph

\begin{abstract}
There is a growing interest in natural antioxidants due to their potential in improving the quality of food and cosmetic products and their health-promoting properties. Distilled spirits contain high amount of ethanol and may be an alternative to the food-grade solvents, while agricultural by-products contain phenolic substances that may have antioxidant properties. This study was therefore conducted to find out if gin, vodka, and tequila flavored spirit, alcoholic beverages with about $40 \%$ ethanol, can extract the phenolic compounds from agricultural by-products, and to determine if the extracts possess the antioxidant activity. Peels of ripe banana (Musa acuminata), ripe mango (Mangifera indica), calamansi (Citrofortunella microcarpa), squash (Cucurbita maxima), ripe pineapple (Ananas comosus), purple yam (Dioscorea alata), and sweet potato (Ipomea batatas) were collected, dried, and ground. The phenolic substances in the plant materials were extracted with alcoholic beverages or $40 \%$ ethanol. The total phenolic content (TPC) of the extracts was determined by means of UV-Vis spectroscopy using Folin-Ciocalteau reagent and gallic acid as reference compound. The antioxidant activity of the extracts was evaluated through the 2,2-diphenyl-1-picrylhydrazyl (DPPH) free radical scavenging assay. Butylated hydroxyanisole (BHA) served as positive control in the DPPH assay. Non-linear regression was applied to the DPPH assay data to estimate the values of median effective concentration $\left(\mathrm{EC}_{50}\right)$. All three alcoholic beverages were able to extract the phenolic materials from the plant samples. However, the ability of vodka and gin to extract the phenolic substances was either statistically comparable or better than $40 \%$ ethanol. The results of the DPPH scavenging assay showed that the M. indica peel had the strongest activity, while C. microcarpa had the weakest scavenging activity. At 1000-ppm level, the antioxidant activity of the $M$. indica peel was comparable with that of BHA, regardless of the solvent used for extraction. Therefore, the M. indica peel can be a source of natural antioxidants and potential substitute to synthetic antioxidants. Both gin and vodka can be used as a substitute for food-compatible solvents.
\end{abstract}

Keywords: phenolics; antioxidant; waste valorization; agricultural by-products; distilled spirits

\section{INTRODUCTION}

Plant phenolics have potential applications in improving the quality of food. The control of the food deterioration due to oxidation of lipids, which leads to the development of off-flavor or odor, is a challenge faced by the food industry. Synthetic antioxidants, such as butylated hydroxytoluene (BHT) and butylated hydroxyanisole (BHA), have been widely used to control the 
autooxidation of lipids and prolong the shelf-life of food products. However, the concerns about the safety of these synthetic substances have been raised, although there have been conflicting reports about the positive and negative effects of these substances on the human and animal health [Botterweck et al., 2000]. Nevertheless, the concerns on the toxicity of these synthetic phenolics have justified the search of natural antioxidants from edible sources. The antioxidant properties of plant phenolics are well known [Kähkönen et al., 1999], making them good candidates as an alternative to the synthetic antioxidants currently used in the food industry.

The processing of fruit and vegetable generates large volume of wastes that can be sources of natural antioxidants. Phenolics are the most abundant secondary metabolites in plants and found in all plant organs [Dai and Mumper, 2010]. Thus, phenolics are present even in the peels and other nonedible parts of fruits and vegetables that ended up as wastes [Dimitrios, 2006]. A review of the worldwide waste generation reports showed that in 2010 the residues from the fruit and vegetable processing industry amounted to as low as $3.5 \mathrm{M}$ metric tons for grapefruit to as high as 130M metric tons for potatoes [Van Dyk et al., 2013]. The same set of data showed that fruit and vegetable processing resulted in losses due to wastes ranging from 3 to $7 \%$ in tomatoes to 40 to $80 \%$ in pineapple. Waste valorization, which is the production of useful chemicals, materials or energy from wastes, is an attractive management option for food processing residues [Arancon et al., 2013]. The recovery of antioxidants from fruit and vegetable wastes has already been demonstrated [Arancon et al., 2013; Federici et al., 2009].

Food grade solvents are expensive and often inaccessible to home-based or small-scale food processing facilities. Laboratory grade solvents may not be fit for human consumption and extraction of natural products using these solvents requires further purification steps if the extracts are meant to be added to food. The use of extracting media from edible sources will enable the direct application of the extracts to food. Alcoholic beverages have traditionally been used in extracting medicinal substances from plant sources [Akinsulire et al., 2007; Egea et al., 2015]. However, the use of alcoholic beverages in the extraction of phenolic substances from plants has not been extensively explored yet.
Distilled beverages are produced from distilling ethanol after the fermentation process and contain high amount of ethanol (about 40\%). Neutral spirits, such as gin and vodka, are clear and colorless distilled beverages the flavor of which comes mainly from their alcohol content [Pauley and Maskell, 2017]. The level of phenolics in these spirits was too low to be measured [Goldberg et al., 1999] while the total antioxidant content was reported to be zero [Yashin et al., 2010].

This study was therefore designed to find out if neutral spirits could extract phenolics from the fruit and vegetable peels and whether the extracts possess the antioxidant activity.

\section{MATERIALS AND METHODS}

\section{Materials and Reagents}

The fruit and vegetable peelings were collected from local markets in the Science City of $\mathrm{Mu}-$ ñoz, Nueva Ecija, Philippines: ripe banana (Musa acuminata), ripe mango (Mangifera indica), calamansi (Citrofortunella microcarpa), pineapple (Ananas comosus), squash (Cucurbita maxima), purple yam (Dioscorea alata), and sweet potato (Ipomoea batatas). The following reagent-grade chemicals were utilized: ethanol and methanol from Sharlau (Spain); 2,2-diphenyl-1-picrylhydrazyl (DPPH) and butylated hydroxianisole (BHA) from Sigma-Aldrich (Switzerland); gallic acid and ascorbic acid from Himedia Laboratories (India); sodium carbonate and Folin-Ciocalteau phenol reagent from Techno Pharmachem (India). The following distilled spirits were used: gin (locally manufactured, 80 proof), vodka (imported, 80 proof), and tequila flavored spirit (TFS, locally manufactured, 80 proof).

\section{Extraction}

The plant samples were cleaned, washed, cut into small pieces, air-dried and ground. The ground fruit and vegetable peel samples were separately extracted with $40 \%$ ethanol, gin, vodka or TFS (1 g plant material: $10 \mathrm{~mL}$ solvent) at room temperature for 48 hours. The extract was separated from the residue by filtration. The crude extract was collected and then placed in glass bottles that were protected from light and stored in the refrigerator until ready for analysis. 


\section{Determination of Total Phenolic using Folin-Ciocalteau Reagent}

The method used by Musa and Abdullah [2011] for the determination of total phenolic content (TPC) was applied with a slight modification. A total of four hundred microliter $(400 \mu \mathrm{L})$ of extract was added with $800 \mu \mathrm{L}$ of distilled water and $1.0 \mathrm{~mL}$ diluted Folin-Ciocalteau phenol reagent (1:10). The solution was set aside for 5 minutes and then added with $1.0 \mathrm{~mL}$ of $7.5 \%(\mathrm{w} / \mathrm{v})$ sodium carbonate. A series of standards of gallic acid was prepared. The absorbance of the extracts and the standard solutions at $765 \mathrm{~nm}$ were read using Spectrophotometer 1500 (Unico, USA). The total phenolic content (TPC) in the plant extract was expressed in milligram of gallic acid equivalent per gram dry weight of sample (mg GAE/DW).

\section{Determination of Antioxidant Activity using DPPH Radical Scavenging Method}

The 2,2-diphenyl-1-picrylhydrazyl (DPPH) radical scavenging activity assay described by Chan, Lim, and Omar [2007] was performed with minor modification. Different solutions of the extracts $(1000 \mathrm{ppm}, 100 \mathrm{ppm}, 10 \mathrm{ppm}, 1 \mathrm{ppm}$, $0.1 \mathrm{ppm}$ and $0.01 \mathrm{ppm}$ ) were prepared, while the DPPH solution was made by dissolving $6.0 \mathrm{mg}$ of DPPH in $100 \mathrm{~mL}$ methanol. Exactly $1.5 \mathrm{~mL}$ of extract was added into the test tube containing $2.5 \mathrm{~mL}$ of DPPH solution. BHA served as standard. The mixture was shaken vigorously and left to stand in the dark for 30 minutes. The absorbance at $517 \mathrm{~nm}$ of the solution was measured in the Spectrophotometer 1500 (Unico, USA). The scavenging activity of each extract of DPPH radical was calculated using the following equation:

$$
\begin{gathered}
D P P H \text { scavenging activity }= \\
=\left(\frac{A b s_{\text {blank }}-A b s_{\text {sample }}}{A b s_{\text {blank }}}\right) \times 100
\end{gathered}
$$

The scavenging activity of the extracts was expressed as the $\mathrm{EC}_{50}$ values, which were estimated by applying nonlinear regression (sigmoidal dose-response) to the data.

\section{Data Analysis}

All the experiments were conducted in triplicate. The statistical and nonlinear regression analyses were performed using Prism 7.0 (GraphPad Software, La Jolla, CA, USA).

\section{RESULTS}

All three alcoholic beverages were able to extract the phenolic components from the fruit and vegetable peels (Table 1). However, the ability of vodka and gin to extract the phenolic substances was either statistically comparable to or better than that of $40 \%$ laboratory grade ethanol. The tequila flavored spirit, on the other hand, was able to extract lower or statistically similar amount of phenolics compared to $40 \%$ ethanol. The labels of the three distilled spirits indicated that the ethanol content in the beverages was $40 \%$ ( 80 proof). The results suggest that there are other factors that determine the ability of the distilled spirits to extract phenolics from plant materials aside from their ethanol content.

Regardless of the extracting solvent, ripe mango (M. indica) peel achieved the extracts with the highest total phenolic content $(34.30 \pm 0.85$ to $38.65 \pm 0.48 \mathrm{mg}$ GAE/g DW). The extract from squash (C. maxima) peel was found to

Table 1. Total phenolic content (mg GAE/g $D W$ ) of various agricultural by-products extracted with different

\begin{tabular}{|c|c|c|c|c|}
\hline \multirow{2}{*}{$\begin{array}{l}\text { Agricultural } \\
\text { by-products }\end{array}$} & \multicolumn{4}{|c|}{ Total phenolic content (mg GAE/g DW) } \\
\hline & Gin & Vodka & Tequila flavored spirit & $40 \%$ Ethanol (control) \\
\hline A. comosus & $9.63(0.84)^{* * *}$ & $10.65(0.30)^{\star * *}$ & $4.85(1.02)$ & $6.25(0.18)$ \\
\hline C. maxima & $3.02(0.62)^{*}$ & $2.11(0.17)$ & $1.38(0.19)$ & $2.15(0.29)$ \\
\hline C. microcarpa & $18.07(0.51)$ & $21.15(0.80)^{\star \star *}$ & $11.86(1.00)^{\star * *}$ & $17.11(0.47)$ \\
\hline D. alata & $5.93(0.61)^{* * \star}$ & $4.79(0.68)^{\star \star}$ & $2.06(0.20)$ & $2.52(0.56)$ \\
\hline I. batatas & $14.23(0.54)$ & $16.63(0.78)^{\star * *}$ & $9.93(0.07)^{* \star \star}$ & $14.65(0.29)$ \\
\hline M. acuminata & $12.10(0.05)^{* * *}$ & $12.64(0.61)^{\star * *}$ & $5.85(0.61)^{* * *}$ & $8.85(0.27)$ \\
\hline M. indica & $34.30(0.85)$ & $38.65(0.48)^{* *}$ & $35.05(0.81)$ & $35.45(0.69)$ \\
\hline
\end{tabular}
distilled spirits or $40 \%$ ethanol

In a row, means that are significantly different from the control (40\% ethanol) based on one-way ANOVA followed by Dunnett's Test are labeled with * $(\mathrm{p} \leq 0.05),{ }^{* *}(\mathrm{p} \leq 0.01)$, and $* * *(\mathrm{p} \leq 0.001)$. 
have the lowest phenolics content $(1.38 \pm 0.19$ to $3.02 \pm 0.62 \mathrm{mg} \mathrm{GAE} / \mathrm{g} \mathrm{DW}$ ). The following sequence shows the plant materials in decreasing order of their phenolics content: $M$. indica $>C$. microcarpa $>$ I. batatas $>$ M. acuminata $>$ A. comosus $>$ D. alata $>$ C. maxima.

The antioxidant property of the extracts was evaluated by the 2,2-diphenyl-1-picrylhydrazyl (DPPH) scavenging assay. Different concentrations of the extract were tested and the half maximal effective concentration $\left(\mathrm{EC}_{50}\right)$ values were estimated from the dose-response curves. The dose-response curves of the vodka extracts (Fig. 1A) are found to the right of the curves for BHA, indicating that the synthetic antioxidant exhibited stronger DPPH scavenging activity than any of the extracts. The curve for $M$. indica is closest to the curve for the positive control, while the curve for C. microcarpa is farthest. A similar trend was observed for the gin extracts (Fig. 1B). The positive control, BHA, was found to have the lowest $\mathrm{EC}_{50}$ value (Table 2), suggesting that it is the most effective in scavenging DPPH among the samples tested. Regardless of the solvent, $M$. indica showed the lowest $\mathrm{EC}_{50}$ value among the plant extracts while C. microcarpa had the highest $\mathrm{EC}_{50}$ value (Table 2). Taken together, these findings indicate that $M$. indica has the strongest activity among the extracts, while C. microcarpa has the weakest scavenging capacity.

The antioxidant activity of the extracts at 1000 and 100 ppm concentrations was compared to the activity of BHA at similar concentrations. At $1000 \mathrm{ppm}$ concentration, the $M$. indica extract exhibited DPPH scavenging activity that was statistically similar to that of BHA (Table 3). All the other extracts at $1000 \mathrm{ppm}$ concentration had significantly lower activity than the positive control. At $100 \mathrm{ppm}$ level, the scavenging activity of the extracts exhibited significantly weaker activity than the positive control (Table 3).

\section{DISCUSSION}

Because phenolics are abundant and ubiquitous in plants, their presence in the fruit and vegetable peels is not unexpected. The extraction of phenolic antioxidant compounds in the peels of mango (M. indica) [Ajila et al., 2010; Ajila et al. 2007a; Ajila et al. 2007b; Ashoush and Gadallah, 2011; Kim et al., 2010; Ribeiro et al., 2008; Sogi et al., 2013], banana (M. acuminata)
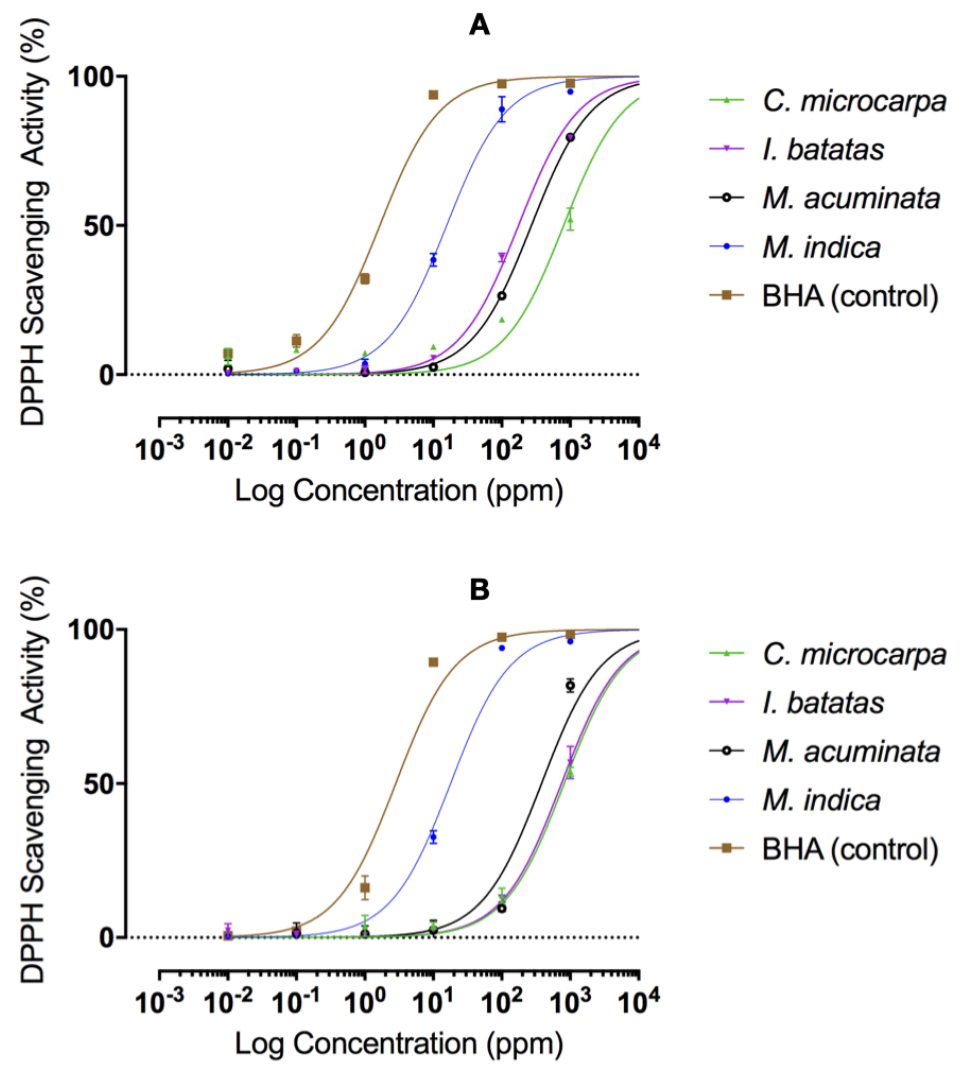

Figure 1. Concentration-response curves of the fruit and vegetable peels extracted with vodka (A) and gin (B) against their DPPH scavenging activity 
Table 2. Estimates of the half maximal effective concentrations $\left(\mathrm{EC}_{50}, \mathrm{ppm}\right)$ of the $\mathrm{DPPH}$ scavenging activity of the different extracts

\begin{tabular}{|l|c|c|}
\hline \multirow{2}{*}{$\begin{array}{c}\text { Agricultural } \\
\text { by-products }\end{array}$} & \multicolumn{2}{|c|}{$\mathrm{EC}_{50}(\mathrm{ppm})$} \\
\cline { 2 - 3 } M. indica & Vodka & Gin \\
\hline I. batatas & 15.67 & 17.89 \\
\hline M. acuminata & 175.5 & 745.9 \\
\hline C. microcarpa & 271.1 & 381.1 \\
\hline BHA (control) & 801.5 & 815.9 \\
\hline
\end{tabular}

[Babbar et al., 2011; González-Montelongo et al., 2010; Samonte and Trinidad, 2013], sweet potato (I. batatas) [Truong et al., 2007], calamansi ( $C$. microcarpa) [Samonte and Trinidad, 2013], and pineapple (A. comosus) [de Oliveira et al., 2009; Diaz-Vela et al., 2013] has previously been reported. The phenolic content of peel and flesh of purple yam (D. alata) [Lubag et al., 2008] and squash (C. maxima) [Javaherashti et al., 2012; Sopan et al., 2014] has also been previously determined. Several studies have also demonstrated that phenolics are present in the residues obtained in the processing of fruits and vegetables [Babbar et al., 2011; de Oliveira et al., 2009; Kanatt et al., 2010; Llorach et al., 2002; Moo-Huchin et al., 2015; Shui and Leong, 2006; Tow et al., 2011].

Aside from evaluating the phenolics content of the fruit and vegetable wastes, another goal of the present study was to find edible solvents for the extraction of phenolic compounds from plants. It was hypothesized that neutral spirits, which have about $40 \%$ ethanol, were suitable extracting solvents. The results showed that gin and vodka are as good or better than the $40 \%$ reagent grade ethanol in extracting phenolics from the fruit and vegetable peels. Thus, they may be utilized in preparing phenolic extracts instead of the expensive food grade solvent. A technology based on the use of edible solvents may be developed for the application of natural antioxidants in small-scale and home- or rural-based food industries.

Although the three alcoholic beverages investigated have equal ethanol content (40\%), their ability to extract the phenolic substances differed. This may be attributed to the other substances present in the beverage. For instance, the tequila flavored spirit used in the study contains flavors and essences, according to its manufacturer. The gin used in this study is of Dutch type, which means malted barley and maize or rye served as raw material in the production of malt-wine that is redistilled with juniper berries and other botanicals [Clutton and Evans, 1978]. Vodka is produced from the fermentation of agricultural products such as potatoes and grains, and unlike gin, the neutral alcohol obtained after fermentation is subjected to the removal of volatile congeners resulting in a beverage that is almost flavorless and odorless [Pauley and Maskell, 2017]. Higher alcohols, including 1-propanol (n-propyl alcohol), 1-butanol (n-butyl alcohol), 2-butanol (sec-butyl alcohol), isobutanol (2-methyl-1-propanol) and isoamyl alcohol (3-methyl1-butanol), are also present in alcoholic beverages [Lachenmeier et al., 2008]. They may also have influenced the ability of the distilled spirits to extract phenolics from plant materials and help explain why gin and vodka had better extracting power for phenolics relative to the control solvent ( $40 \%$ ethanol). A major limitation of the present work is the absence of the data regarding the flavor and higher alcohol constituents of the distilled spirits and an investigation of how these modify the extraction of phenolics from the plant samples.

When similar concentrations of the extracts were tested for their DPPH scavenging activity, the strongest activity was observed in mango (M. indica) peel while the weakest

Table 3. The DPPH scavenging activity of gin and vodka extracts from fruit and vegetable peels at 1000 and $100 \mathrm{ppm}$, compared with the activity of butylated hydroxyanisole (BHA)

\begin{tabular}{|l|c|c|c|c|}
\hline \multirow{2}{*}{ Agricultural by-products } & \multicolumn{4}{|c|}{ DPPH scavenging activity (\%) } \\
\cline { 2 - 5 } & \multicolumn{2}{|c|}{$1000 \mathrm{ppm}$} & Gin & Vodka \\
\cline { 2 - 5 } & Gin & Vodka & $94.03 \pm 0.45^{*}$ & $88.95 \pm 4.23^{*}$ \\
\hline M. indica & $96.06 \pm 0.17$ & $94.88 \pm 0$ & $12.65 \pm 1.14^{* * *}$ & $39.29 \pm 1.41^{* * *}$ \\
\hline I. batatas & $56.85 \pm 5.24^{* * *}$ & $79.50 \pm 0.68^{* * *}$ & $13.57 \pm 2.40^{* * *}$ & $18.50 \pm 0.10^{* * *}$ \\
\hline C. microcarpa & $53.88 \pm 1.47^{* * *}$ & $52.11 \pm 3.67^{* * *}$ & $9.39 \pm 1.04^{* * *}$ & $26.39 \pm 0.65^{* * *}$ \\
\hline M. acuminata & $81.80 \pm 2.13^{* * *}$ & $79.53 \pm 0.37^{* * *}$ & $97.52 \pm 0.15$ & $97.53 \pm 1.70$ \\
\hline BHA (control) & $98.40 \pm 0.06$ & $97.63 \pm 0.10$ & \\
\hline
\end{tabular}

In a column, means that are significantly different from the control (BHA) based on one-way ANOVA followed by Dunnett's Test are labeled with * $(\mathrm{p} \leq 0.05), * *(\mathrm{p} \leq 0.01)$, and $* * *(\mathrm{p} \leq 0.001)$. 
activity was exhibited by calamansi (C. microcarpa) peel. The results of the DPPH activity assay agree with a previous report that among mango ( $M$. indica), banana (M. acuminata) and calamansi (C. microcarpa) peels, mango had the strongest activity while calamansi had the weakest [Samonte and Trinidad, 2013]. The mango (M. indica) peel extract was found to exert statistically comparable antioxidant activity with BHA at $1000 \mathrm{ppm}$ level, but not at $100 \mathrm{ppm}$. This is expected since crude extract was used. Since other substances in the crude extract do not possess the antioxidant property, a large amount of the crude extract is needed for its activity to become comparable with the positive control.

\section{CONCLUSION}

Agricultural residues are rich in phenolics with antioxidant properties. Although alcoholic beverages have traditionally been used in herbal medicine preparation, their use in the extraction of phenolic compounds has not received much attention. In this study, the ability of gin, vodka, and tequila flavored spirits, which contain $40 \%$ alcohol, to extract phenolics from the selected fruit and vegetable wastes was evaluated. Although the three beverages were able to extract the phenolic substances from plant materials, gin and vodka had comparable or better extraction power compared with $40 \%$ reagent grade ethanol. Regardless of the solvent, the mango peel enabled to obtain the extracts with the highest phenolics content and strongest antioxidant activity. The findings may serve as basis for the development of technology for the utilization of natural antioxidant from waste materials using edible solvents.

\section{Acknowledgement}

This research received support from the Commission on HigherEducation(CHED), Philippines.

\section{REFERENCES}

1. Ajila, C. M., Aalami, M., Leelavathi, K., \& Prasada Rao, U. J. S. 2010. Mango peel powder: A potential source of antioxidant and dietary fiber in macaroni preparations. Innovative Food Science and Emerging Technologies, 11, 219-224.

2. Ajila, C. M., Bhat, S. G., \& Prasada Rao, U. J. S. 2007a. Valuable components of raw and ripe peels from two Indian mango varieties. Food Chemistry, 102, 1006-1011.

3. Ajila, C. M., Naidu, K. A., Bhat, S. G., \& Prasada Rao, U. J. S. 2007b. Bioactive compounds and antioxidant potential of mango peel extract. Food Chemistry, 105, 982-988.

4. Akinsulire, O. R., Aibinu, I. E., Adenipekun, T., Adelwotan, T., \& Odugbemi, T. 2007. In vitro antimicrobial activity of crude extracts from plants. African Journal of Traditional, Complimentary and Alternative Medicine, 4(3), 338-344.

5. Arancon, R. A. D., Lin, C. S. K., Chan, K. M., Kwan, T. H., \& Luque, R. 2013. Advances on waste valorization: new horizons for a more sustainable society. Energy Science \& Engineering, 1, 53-71.

6. Ashoush, I. S., \& Gadallah, M. G. E. 2011. Utilization of mango peels and seed kernels powders as sources of phytochemicals in biscuit. World Journal of Dairy \& Food Sciences, 6(1), 35-42.

7. Babbar, N., Oberoi, H. S., Uppal, D. S., \& Patil, R. T. 2011. Total phenolic content and antioxidant capacity of extracts obtained from six important fruit residues. Food Research International, 44, 391-396.

8. Botterweck, A. A., Verhagen, H., Goldbohm, R. A., Kleinjans, J., \& van den Brandt, P. A. 2000. Intake of butylated hydroxyanisole and butylated hydroxytoluene and stomach cancer risk: Results from analyses in the Netherlands cohort study. Food and Chemical Toxicology, 38(7), 599-605.

9. Chan, E., Lim, Y., \& Omar, M. 2007. Antioxidant and antibacterial activity of leaves of Etlingera species (Zingiberaceae) in Peninsular Malaysia. Food Chemistry, 104(4), 1586-1593.

10. Clutton, D. W., \& Evans, M. B. 1978. The flavour constituents of gin. Journal of Chromatography, 167, 409-419.

11. Dai, J., \& Mumper, R. J. 2010. Plant phenolics: Extraction, analysis and their antioxidant and anticancer properties. Molecules, 15, 7313-7352.

12. de Oliveira, A. C., Valentim, I. B., Silva, C. A., Bechara, E. J. H., Barros, M. P. de, Mano, C. M., \& Goulart, M. O. F. 2009. Total phenolic content and free radical scavenging activities of methanolic extract powders of tropical fruit residues. Food Chemistry, 115, 469-475.

13. Diaz-Vela, J., Totosaus, A., Cruz-Guerrero, A. E., \& De Lourdes Pérez-Chabela, M. 2013. In vitro evaluation of the fermentation of added-value agroindustrial by-products: Cactus pear (Opuntia ficus-indica L.) peel and pineapple (Ananas comosus) peel as functional ingredients. International Journal of Food Science and Technology, 48(7), 1460-1467.

14. Dimitrios, B. 2006. Sources of natural phenolic antioxidants. Trends in Food Science and Technology, 17(9), 505-512. 
15. Egea, T., Signorini, M. A., Bruschi, P., Rivera, D., Obon, C., Alcaraz, F., \& Palazon, J. A. 2015. Spirits and liqueurs in European traditional medicine: Their history and ethnobotany in Tuscany and Bologna (Italy). Journal of Ethnopharmacology, 175, 241-255.

16. Federici, F., Fava, F., Kalogerakis, N., \& Mantzavinos, D. 2009. Valorisation of agro-industrial by-products, effluents and waste: Concept, opportunities and the case of olive mill waste waters. Journal of Chemical Technology and Biotechnology, 84, 895-900.

17. Goldberg, D. M., Hoffman, B., Yang, J., \& Soleas, G. J. 1999. Phenolic constitents, furans, and total antioxidant status of distilled spirits. Journal of Agricultural and Food Chemistry, 47, 3978-3985.

18. González-Montelongo, R., Gloria Lobo, M., \& González, M. 2010. Antioxidant activity in banana peel extracts: Testing extraction conditions and related bioactive compounds. Food Chemistry, 119(3), 1030-1039.

19. Javaherashti, M., Ghasemnezhad, M., Lahiji, H. S., \& Shiri, M. A. 2012. Comparison of nutritional value and antioxidant compounds of some winter pumpkin (Cucurbita $S p$ ) species fruits in Iran. Advances in Environmental Biology, 6(10), 2611-2616.

20. Kähkönen, M. P., Hopia, A. I., Vuorela, H. J., Rauha, J.-P., Pihlaja, K., Kujala, T. S., \& Heinonen, M. 1999. Antioxidant Activity of Plant Extracts Containing Phenolic Compounds. Journal of Agricultural and Food Chemistry, 47, 3954-3962.

21. Kanatt, S. R., Chander, R., \& Sharma, A. 2010. Antioxidant and antimicrobial activity of pomegranate peel extract improves the shelf life of chicken products. International Journal of Food Science and Technology, 45, 216-222.

22. Kim, H., Moon, J. Y., Kim, H., Lee, D. S., Cho, M., Choi, H. K., Kim, Y. S., Mosaddik, A., \& Cho, S. K. 2010. Antioxidant and antiproliferative activities of mango (Mangifera indica L.) flesh and peel. Food Chemistry, 121, 429-436.

23. Lachenmeier, D.W., Haupt, S., \& Schulz, K. 2008. Defining maximum levels of higher alcohols in alcoholic beverages and surrogate alcohol products. Regulatory Toxicology and Pharmacology, 50(3), 313-321.

24. Llorach, R., Espín, J. C., Tomás-Barberán, F. A., \& Ferreres, F. 2002. Artichoke (Cynara scolymus L.) byproducts as a potential source of health-promoting antioxidant phenolics. Journal of Agricultural and Food Chemistry, 50, 3458-3464.

25. Lubag, A.J.M., Laurena, A.C., \& Tecson-mendoza, E.M. 2008. Antioxidants of purple and white greater yam (Dioscorea alata L.) varieties from the Philippines. Philippine Journal of Science, 137(1), 61-67.

26. Moo-Huchin, V. M., Moo-Huchin, M. I., EstradaLeón, R. J., Cuevas-Glory, L., Estrada-Mota, I. A., Ortiz-Vázquez, E., Betancur-Ancona, D., \&
Sauri-Duch, E. 2015. Antioxidant compounds, antioxidant activity and phenolic content in peel from three tropical fruits from Yucatan, Mexico. Food Chemistry, 166, 17-22.

27. Musa, K. H., \& Abdullah, A. 2011. Antioxidant activity of pink-flesh guava (Psidium guajava L.): Effect of extraction techniques and solvents. Food Analytical Methods, 4, 100-107.

28. Pauley, M., \& Maskell, D. 2017. Mini-review: The role of Saccharomyces cerevisiae in the production of gin and vodka. Beverages, 3, 13,

29. Ribeiro, S.M.R., Barbosa, L.C.A., Queiroz, J.H., Knödler, M., \& Schieber,A. 2008. Phenolic compounds and antioxidant capacity of Brazilian mango (Mangifera indica L.) varieties. Food Chemistry, 110, 620-626.

30. Samonte, A.P.L., \& Trinidad, T.P. 2013. Dietary fiber, phytonutrients and antioxidant activity of common fruit peels as potential functional food ingredient. Journal of Chemistry and Chemical Engineering, 7, 70-75.

31. Shui, G., \& Leong, L. P. 2006. Residue from star fruit as valuable source for functional food ingredients and antioxidant nutraceuticals. Food Chemistry, 97(2), 277-284.

32. Sogi, D. S., Siddiq, M., Greiby, I., \& Dolan, K. D. 2013. Total phenolics, antioxidant activity, and functional properties of "Tommy Atkins" mango peel and kernel as affected by drying methods. Food Chemistry, 141(3), 2649-2655.

33. Sopan, B.A., Vasantrao, D.N., \& Ajit, S.B. 2014. Total phenolic content and antioxidant potential of Cucurbita maxima (Pumpkin) powder. International Journal of Pharmaceutical Sciences and Research, 5(5), 1903-1907.

34. Tow, W. W., Premier, R., Jing, H., \& Ajlouni, S. 2011. Antioxidant and antiproliferation effects of extractable and nonextractable polyphenols isolated from apple waste using different extraction methods. Journal of Food Science, 76(7).

35. Truong, V. D., McFeeters, R. F., Thompson, R. T., Dean, L. L., \& Shofran, B. 2007. Phenolic acid content and composition in leaves and roots of common commercial sweetpotato (Ipomea batatas L.) cultivars in the United States. Journal of Food Science, 72(6), 343-349.

36. Van Dyk, J. S., Gama, R., Morrison, D., Swart, S., \& Pletschke, B. I. 2013. Food processing waste: Problems, current management and prospects for utilisation of the lignocellulose component through enzyme synergistic degradation. Renewable and Sustainable Energy Reviews, 26, 521-531.

37. Yashin, Y. I., Nemzer, B. V., Ryzhnev, V. Y., Yashin, A. Y., Chernousova, N. I., \& Fedina, P. A. 2010. Creation of a databank for content of antioxidants in food products by an amperometric method. Molecules, 15, 7450-7466. 